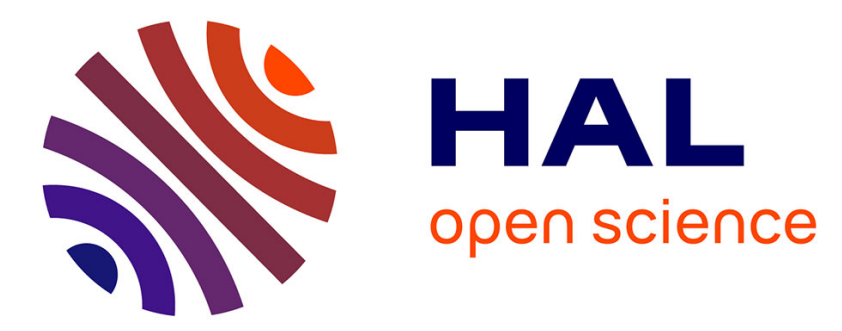

\title{
A fluorogenic BODIPY molecular rotor as an apoptosis marker
}

\author{
Ashokkumar Pichandi, Anila Ashoka, Mayeul Collot, Amitava Das, Andrey \\ Klymchenko
}

\section{- To cite this version:}

Ashokkumar Pichandi, Anila Ashoka, Mayeul Collot, Amitava Das, Andrey Klymchenko. A fluorogenic BODIPY molecular rotor as an apoptosis marker. Chemical Communications, 2019, 55 (48), pp.6902-6905. 10.1039/C9CC03242H . hal-02271513

\section{HAL Id: hal-02271513 \\ https://hal.science/hal-02271513}

Submitted on 26 Aug 2019

HAL is a multi-disciplinary open access archive for the deposit and dissemination of scientific research documents, whether they are published or not. The documents may come from teaching and research institutions in France or abroad, or from public or private research centers.
L'archive ouverte pluridisciplinaire HAL, est destinée au dépôt et à la diffusion de documents scientifiques de niveau recherche, publiés ou non, émanant des établissements d'enseignement et de recherche français ou étrangers, des laboratoires publics ou privés. 


\title{
A FLUOROGENIC BODIPY MOLECULAR ROTOR AS APOPTOSIS MARKER
}

\author{
Pichandi Ashokkumar, ${ }^{a \dagger}$ Anila Hoskere Ashoka, ${ }^{\mathrm{a}, \mathrm{b}+}$ Mayeul Collot, ${ }^{\mathrm{a} *}$ Amitava Das, ${ }^{\mathrm{c*}}$ Andrey S. Klymchenko ${ }^{\mathrm{a} *}$ \\ a. Laboratoire de Bioimagerie et Pathologies, UMR 7021 CNRS, Faculté de Pharmacie, Université de Strasbourg, Strasbourg CS 60024 , France. \\ E-mail : andrey.klymchenko@unistra.fr; mayeul.collot@unistra.fr \\ b. CSIR-National Chemical Laboratory, Pune 411008, India.
}

c. CSIR-Central Salt \& Marine Chemicals Research Institute, Bhavnagar 364002, Gujarat, India. E-mail : a.das@csmcri.res.in

† These authors contributed equally to this work.

Electronic Supplementary Information (ESI) available: Detailed experimental procedures and analytical data for all the compounds. See DOI: $10.1039 / \mathrm{C} 9 \mathrm{CC} 03242 \mathrm{H}$

Based on BODIPY molecular rotor and zinc-dipicolylamine receptor, we designed a fluorogenic probe for detection of apoptosis. Being poorly emissive in solution and with healthy cells, it selectively binds phosphatidylserine of early apoptotic cells and internalizes into late apoptoric cells, lighting up its green fluorescence.

Cell plasma membranes are asymmetric, wherein the zwitterionic phosphatidylcholine (PC) is present in the outer leaflet of the bilayer and the anionic phosphatidylserine (PS) is exclusively located in the inner leaflet. ${ }^{1-5}$ During the early stages of apoptosis, the activity of scramblases increases, leading to the exposure of PS on the cell surface. ${ }^{6-9}$ The presence of anionic PS on the cell surface is a hallmark of apoptosis and it is responsible for the daily clearance of dead cells from the body by macrophages. ${ }^{10,11}$ Moreover, the therapeutic efficacy of the anticancer drugs could be determined by monitoring the apoptosis. ${ }^{12}$ Hence, apoptosis detection is very important from the biological and clinical standpoint.

A number of methods were developed for apoptosis detection, which include monitoring the caspase activation, ${ }^{13-15}$ DNA fragmentation, ${ }^{16}$ activity of mitochondria, ${ }^{17,18}$ or changes in lipid organization at the outer membrane leaflet. ${ }^{19,20}$ One of the most widely used methods is based on fluorescently labelled Annexin V, a calcium-dependent protein with a high-affinity for PS ( $\mathrm{K}_{\mathrm{d}}=$ $0.1 \mathrm{nM}$ ) on the surface of apoptotic cells. ${ }^{21}$ However, it has certain limitations, ${ }^{22}$ such as short shelf life and relatively slow binding, ${ }^{23,24}$ which requires millimolar concentrations of extracellular $\mathrm{Ca}^{2+} .25$ In live cell imaging, washing steps are required to remove the unbound Annexin $\mathrm{V}$ protein, a source of background fluorescence. Differentiation between early and late apoptosis is not possible with Annexin $V$, as often the case with many reported probes. ${ }^{15,19,20,26}$ Recently, fluorescently labelled cationic dipicolylamine-zinc (DPA-Zn) complexes were reported as the alternatives to Annexin $V$ reagents. ${ }^{26}$ These DPA-Zn complexes interact strongly and specifically with anionic PS-rich membranes, allowing the apoptosis detection. However, most of these probes suffer from intrinsic fluorescence ${ }^{27-29}$ and the probes that fluoresce only after PS binding are still rare in the literature. ${ }^{30-32}$ Moreover, differentiation of early vs. late stage apoptosis by these probes remains a challenge. ${ }^{30}$

Fluorogenic probes that turn ON their fluorescence upon interaction with the target are useful for background-free imaging. ${ }^{33}$ One such approach to achieve turn ON response is to use the molecular rotors, dyes undergoing intramolecular rotation that provides an efficient pathway for the nonradiative relaxation. ${ }^{34-37}$ Importantly, an increase in the surrounding viscosity slows down this rotation, resulting in their fluorescence turn-ON. Molecular rotors were successfully used as viscosity probes in live cells, 36,38 cell membranes, ${ }^{39,40}$ as well as fluorogenic reporters of protein assembly ${ }^{41}$ and interactions of nucleic acids. ${ }^{42}$ An attractive approach is to convert molecular rotors into turn ON probes for detecting biomolecular targets, although it was only realized for sensing oxytocin receptor. ${ }^{43}$

Herein, based on BODIPY molecular rotor, we designed a fluorogenic probe for apoptosis detection (BPDPA-Zn, Scheme 1). BPDPA-Zn showed turn-ON fluorescence response upon binding to negatively charged PS-rich membranes in early apoptotic cells and strong intracellular fluorescence in late apoptotic cells, which allowed distinguishing them with good signal to background ratio.

BPDPA-Zn probe is composed of three functional parts: (i) a BODIPY-based molecular rotor, the fluorophore exhibiting strong viscosity dependent emission; ${ }^{34-39}$ (ii) a recognition unit for PS based on DPA-Zn; (iii) a PEG-12 spacer connecting the dye with the recognition unit. The PEG spacer was previously shown to not only improve the solubility of probes, but also prevent their nonspecific interactions with cell plasma membranes. ${ }^{44}$ To obtain BPDPA-Zn, a BODIPY molecular rotor bearing carboxy group was first synthesized and then coupled with a PEG-12 amino-azide spacer, giving azide derivative 1 (Scheme 1a, see ESIt for details). Then, bis-dipicolylamine (bis-DPA) ligand, bearing phenol function, was prepared ${ }^{45}$ and further $O$-alkylated with propargyl bromide, yielding alkyne derivative $\mathbf{2}$. Azide-alkyne click reaction of $\mathbf{1}$ and $\mathbf{2}$, followed by complexation with $\mathrm{Zn}\left(\mathrm{NO}_{3}\right)_{2}$ in methanol/water mixture $(1 / 1, v / v)$, resulted in the final probe BPDPA-Zn. 

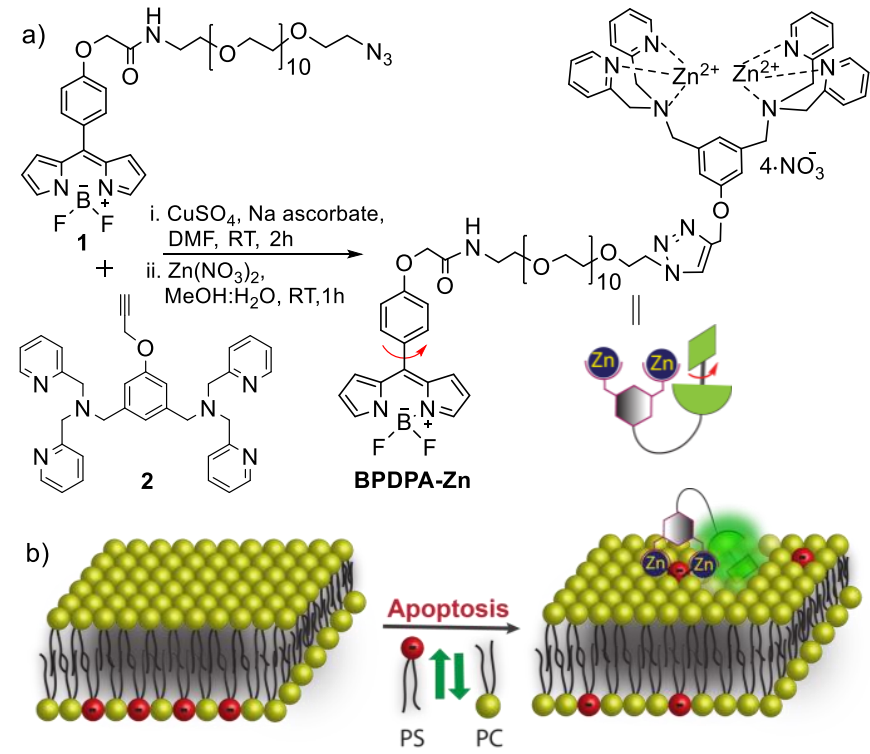

Scheme 1 a) Synthesis of BPDPA-Zn probe; b) Schematic representation of BPDPA-Zn binding to the PS-containing membrane surface and the resultant fluorescence light-up of the molecular rotor.

BPDPA-Zn showed absorption and emission bands centred around 498 and $514 \mathrm{~nm}$, respectively, characteristic for the parent BODIPY dyes ${ }^{46}$ (Fig. S1). To validate the molecular rotor property in the BPDPA-Zn probe, viscosity effect on the fluorescence characteristics was evaluated in methanol/glycerol binary mixture (Fig. 1). The probe showed low fluorescence quantum yield $\left(\Phi_{\mathrm{f}}\right)$ and lifetime $\left(\tau_{\mathrm{f}}\right)$ in pure methanol $\left(\Phi_{\mathrm{f}}=0.02, \tau_{\mathrm{f}}=0.30 \mathrm{~ns}\right)$, suggesting an efficient fluorescence quenching through intramolecular rotation. With increase in viscosity from 0.6 to $1317 \mathrm{cP}, \Phi_{\mathrm{f}}$ increased 29 -fold, while and $\tau_{\mathrm{f}}$ increased from 0.30 to $4.22 \mathrm{~ns}$ (Fig. $1 \mathrm{a}, \mathrm{c}$, Table S1. The radiative $\left(k_{\mathrm{r}}\right)$ and non-radiative $\left(k_{\mathrm{nr}}\right)$ rate constants calculated from the $\Phi_{\mathrm{f}}$ and $\tau_{\mathrm{f}}$ values revealed that $k_{\mathrm{r}}$ remained largely constant $\left(0.06-0.15 \mathrm{~ns}^{-1}\right)$ over the entire viscosity range (Table S1). However, the value of $k_{\mathrm{nr}}$ decreased sharply from 3.27 $\mathrm{ns}^{-1}$ at $0.6 \mathrm{cP}$ to $0.10 \mathrm{~ns}^{-1}$ at $1317 \mathrm{cP}$. These changes in the rate constants confirm that the observed increase in fluorescence efficiency at higher viscosity is due to the suppression of non-radiative processes as reported earlier for the parent BODIPY rotor. ${ }^{36-}$ ${ }^{39,47}$ As expected, we found a linear correlation of log $\Phi_{\mathrm{f}}$ values versus log viscosity according to the Förster-Hoffmann equation with a slope of the plot of 0.6 (Fig. 1C), in agreement with the literature data for BODIPY molecular rotors. ${ }^{48}$ The similar trend was also observed for the logarithmic plot of $\tau_{\mathrm{f}} v s$ viscosity (Fig. 1d). Finally, BPDPA-Zn showed no solvatochromism in both absorption and fluorescence spectra in all the solvents studied (Table S2), suggesting negligible change in its dipole moment on the electronic excitation. $\Phi_{\mathrm{f}}$ remained very low (Table S2, Fig. S2), with only a marginal increase upon decrease in solvent polarity $\left(\Phi_{\mathrm{f}}=0.020\right.$ in methanol $\varepsilon=32.6$, and $\Phi_{\mathrm{f}}=0.065$ in chloroform $\varepsilon=4.81$ ). However, this effect is significantly smaller than that for twisted intramolecular charge transfer (TICT) rotors. ${ }^{34,35,43}$ Hence, similarly to parent BODIPY rotor, BPDPA-Zn directly reports the environment microviscosity irrespectively of the polarity.
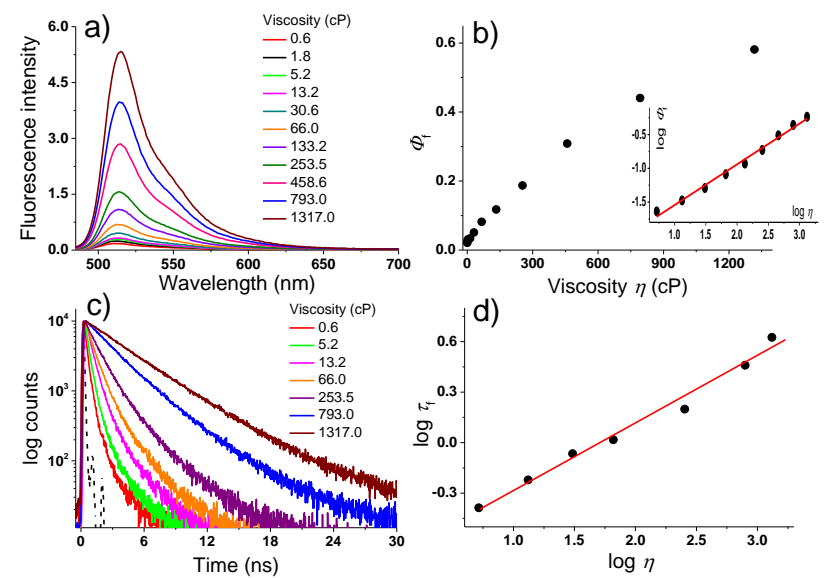

Fig. 1 Fluorescence characterisation of BPDPA-Zn $(1 \mu \mathrm{M})$ in methanol/glycerol mixtures of varied viscosity as shown in the colour code recorded at $20{ }^{\circ} \mathrm{C}$. a) Fluorescence spectra $\left(\lambda_{\text {ex }}=480 \mathrm{~nm}\right)$; b) Plot of fluorescence quantum yield as a function of viscosity. Inset shows the linearity in the selected region of viscosity obtained in the log plot; c) Fluorescence decay profile $\left(\lambda_{\text {ex }}=443 \mathrm{~nm}\right.$ and $\lambda_{\text {em }}=515 \mathrm{~nm}$ ); the dotted line corresponds to the laser profile. d) Log plot of fluorescence lifetime $v s$. viscosity according to the Förster-Hoffmann equation. Estimated measurement errors were $5 \%$ for the quantum yield and $2 \%$ for the lifetime. 
To further study the probe response to PS-rich membranes, we prepared liposomes composed of (i) entirely zwitterionic lipid PC to mimic the uncharged membrane surfaces of healthy cells, and (ii) mixtures of PC and PS to mimic the apoptotic cell surface. The absorption spectrum of BPDPA-Zn in these liposomes showed only limited changes (Fig. S3). On the other hand, a gradual increase in the fluorescence intensity was observed as the fraction of PS increased from 5 to $50 \%$ (Fig. 2a). Then, we carried out studies with bovine serum albumin (BSA, the major component of serum) and other model lipid membranes composed of sphingomyelin/cholesterol (SM/Chol), dioleoylphosphatidylcholine (DOPC) and DOPC/cholesterol. Importantly, BPDPA-Zn did not show any significant enhancement in $\Phi_{\mathrm{f}}$ for BSA or any of the zwitterionic lipid vesicles without PS. The incorporation of polar $\mathrm{PEG}_{12}$ chain in the probe probably helps to prevent the nonspecific interaction of the dye, as it was previously shown with a solvatochromic dye, Nile Red derivative. ${ }^{44}$ This result confirmed that BPDPA-Zn specifically binds to the anionic PS, which induces an insertion of BODIPY molecular rotor into the lipid bilayer. This insertion may sterically hinder the intramolecular rotation of the rotor (Scheme 1), which results in the observed fluorescence enhancement, as in the viscosity dependence experiment. However, the fluorescence enhancement in case of lipid membranes was smaller, because their microviscosity $(140 \pm 40 \mathrm{cP})^{36}$ is much lower than that of glycerol (1410 cP).

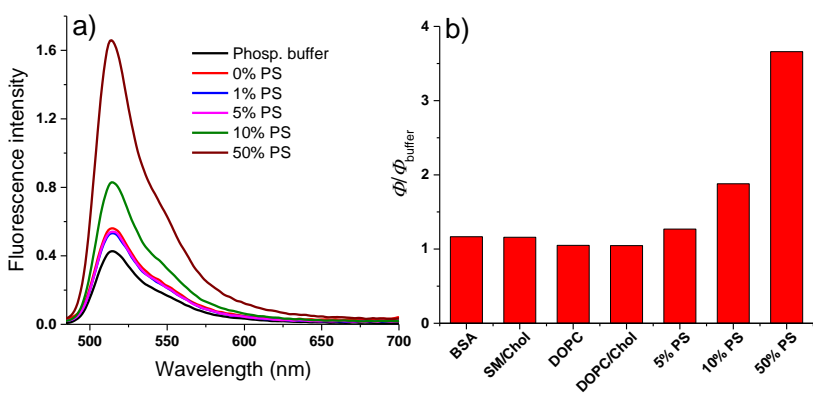

Fig. 2 a) Fluorescence response of BPDPA-Zn $(1 \mu \mathrm{M})$ in phosphate buffer $(20 \mathrm{mM}, \mathrm{pH} 7.4)$ with various large unilamellar vesicles and BSA. a) Fluorescence spectra $\left(\lambda_{\text {ex }}=480 \mathrm{~nm}\right)$ in the presence of vesicles with varied fraction of PS in PC; $b$ ) Ratio of quantum yield in the presence of serum protein or different lipid vesicles to that in phosphate buffer. Concentration of BSA and lipids was 20 and $200 \mu \mathrm{M}$, respectively.

The observed selectivity of the BPDPA-Zn to anionic vesicles inspired us to explore the possibility of using the probe for apoptosis detection. First, HeLa cells were treated with different concentrations of staurosporine for $2 \mathrm{~h}$ to induce early as well as late apoptosis. ${ }^{30,49}$ The cells were subsequently stained with BPDPA-Zn $(1 \mu \mathrm{M})$ and commercially available apoptosis marker based on labelled Annexin V (Alexa Fluor 568 conjugate), which specifically recognizes exposed PS in apoptotic cells. 6,50 For the earlystate apoptosis treatment ( $1 \mu \mathrm{M}$ staurosporine), ${ }^{30}$ only the cells labelled Annexin $\mathrm{V}$ exhibited bright green fluorescence of BPDPA$\mathbf{Z n}$, with good co-localization of both markers at the plasma membrane (Fig 3a). These observations indicated that BPDPA-Zn is able to anchor to the membrane of early-stage apoptotic cells. Treatment of cells with $3 \mu \mathrm{M}$ staurosporine, reported to induce late apoptosis, ${ }^{49}$ resulted in strong intracellular fluorescence of BPDPA-Zn (Fig 3b), in contrast to the labelled Annexin V that remained at the cell surface. Remarkably, healthy HeLa cells observed in the bright field but not labelled with Annexin $V$, showed no fluorescence signal of BPDPA-Zn (Fig. 3). This result confirmed the specificity and efficacy of BPDPA-Zn for the detection of apoptosis.

Next, flow cytometry has been carried out with both BPDPA-Zn and Annexin V Alexa Fluor 568. Normal cells stained with BPDPA-Zn and Annexin showed up in a quadrant Q1 of the dot plot, indicating weak fluorescence signal for both markers (Fig. 4). Whereas, the cells treated with staurosporine at intermediate concentration $(2 \mu \mathrm{M})$ showed significant intensity increase for both markers used separately (in Q2 and Q4). For double-labelling, Annexin-positive cells were also BPDPA-Zn-positive (in Q3), confirming sensitivity of the latter to apoptosis. However, in contrast to Annexin, BPDPA-Zn showed two cell populations (P1 and $\mathrm{P} 2$ ), presumably early and late apoptotic cells. To prove that, we treated the cells with $3 \mu \mathrm{M}$ staurosporine (favouring late apoptosis) and co-stained with propidium iodide (PI), a dead/necrotic cells indicator. As shown in Fig. S4, P1 population of BODIPYpositive cells was PI-negative (Q2), whereas P2 corresponded to PI-positive cells (Q3). Therefore, P1 and P2 can be assigned to early and late apoptotic cells, respectively. Higher intensity in case of late vs early apoptotic cells can be explained by the probe internalisation (Fig. 3), which contributes to the signal enhancement. These results showed that our probe BPDPA-Zn can differentiate early and late apoptosis, which is not possible with the Annexin assay. 


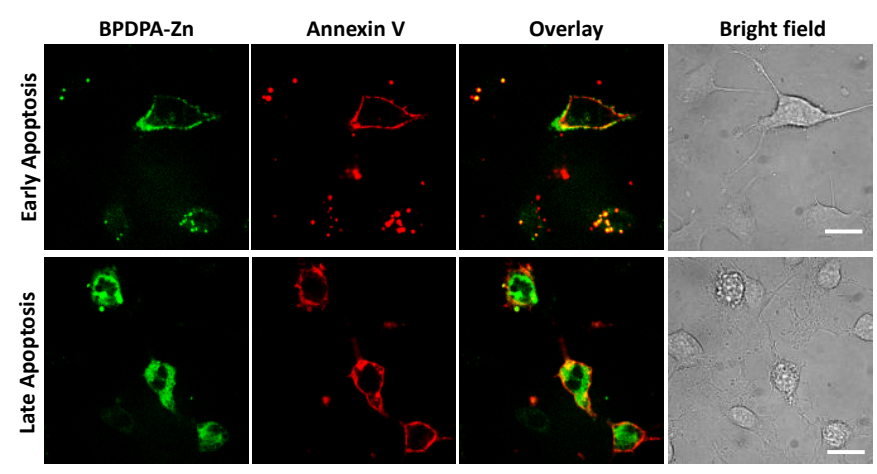

Fig. 3 Fluorescence images of early and late apoptotic HeLa cells induced by 1 and $3 \mu \mathrm{M}$ staurosporine, respectively, for $2 \mathrm{~h}$ at $37^{\circ} \mathrm{C}$, which were stained with BPDPA-Zn ( $1 \mu \mathrm{M}$, green) and Annexin V Alexa Fluor 568 (0.5\% v/v, red). Spinning disk imaging mode was used; BPDPA-Zn and Annexin V Alexa Fluor 568 were excited with 488-and 532-nm lasers, respectively, while emission was detected using $530 / 30$ and $600 / 50 \mathrm{~nm}$ band-pass filters, respectively. Images were captured after 15 minutes incubation at $20^{\circ} \mathrm{C}$ with the probes. Scale bar $=20$ $\mu \mathrm{m}$.

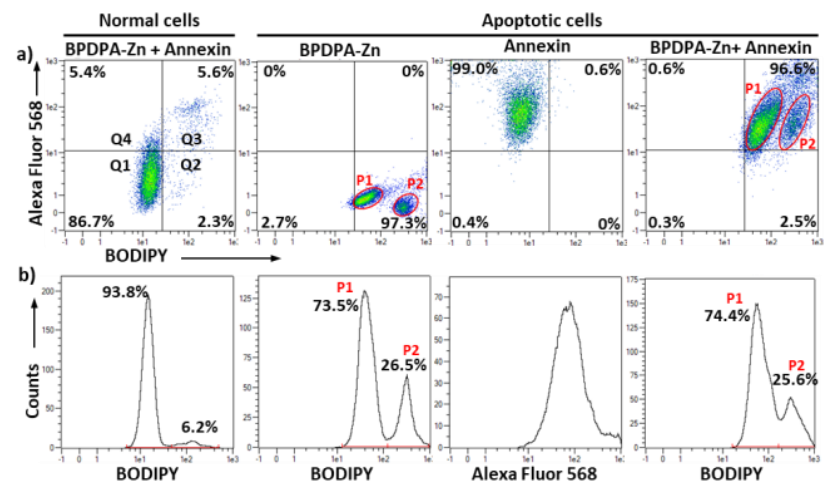

Fig. 4 a) Representative flow cytometry dot plot of normal cells and apoptotic HeLa cells induced by $2 \mu \mathrm{M}$ staurosporine for $2 \mathrm{~h}$ at $37^{\circ} \mathrm{C}$, which were either stained with BPDPA-Zn (1 $\mu \mathrm{M})$, Annexin V Alexa Fluor $568(0.5 \% \mathrm{v} / \mathrm{v})$ or both. b) The corresponding flow cytometry histograms showing cell counts vs. fluorescence intensity for BODIPY or Alexa 568 channel. BODIPY and Aleaxa Fluor 568 were excited at 488- and 561-nm lasers, respectively, while their fluorescence was collected at 525/50 and $615 / 20 \mathrm{~nm}$, respectively. P1 and P2 represents early and late apoptotic cells, respectively.

In summary, we propose an original design of fluorescent probe for detection and differentiation of early and late apoptosis based on fluorogenic viscosity-dependent character of molecular rotors. The developed probe (BPDPA-Zn) is composed of a BODIPY molecular rotor bearing through a $\mathrm{PEG}_{12}$ linker a ligand specific to PS, an anionic lipid exposed in apoptotic cells. The fluorescence quantum yield and the lifetime of the probe confirmed its molecular rotor properties. BPDPA-Zn specifically binds to model lipid membranes containing anionic phospholipid PS, resulting in significant fluorescence enhancement. It lights up apoptotic cells in green fluorescence, while showing no signal in healthy (HeLa) cells. The response of the probe correlates well with commercial apoptosis marker Annexin $\mathrm{V}$ and in addition, the probe differentiates between early and late apoptotic cells, due to its capacity to enter the latter. To the best of our knowledge, this is the first report on designing an apoptosis probe based on a molecular rotor dye and the first PS-targeting probe that distinguishes early and late apoptotic cells based on fluorescence intensity. Our results open a route to fluorogenic probes for apoptosis detection and suggest molecular rotors as promising building blocks for fluorogenic biosensors.

This work was supported by the European Research Council ERC Consolidator grant BrightSens 648528. AHA acknowledge IndoFrench Centre for the Promotion of Advanced Research for Raman-Charpak fellowship.

\section{Conflicts of interest}

There are no conflicts to declare.

\section{Notes and references}

1 A. Zachowski, Biochem. J., 1993, 294, 1-14.

2 P. F. Devaux and A. Zachowski, Chem. Phys. Lipids, 1994, 73, 107-120.

3 J. D. Nickels, J. C. Smith and X. Cheng, Chem. Phys. Lipids, 2015, 192, 87-99.

4 M. Murate, M. Abe, K. Kasahara, K. Iwabuchi, M. Umeda and T. Kobayashi, J. Cell Sci., 2015, 128, 1627-1638.

5 M. Murate and T. Kobayashi, Chem. Phys. Lipids, 2016, 194, 58-71. 
6 S. J. Martin, C. P. Reutelingsperger, A. J. McGahon, J. A. Rader, R. C. van Schie, D. M. LaFace and D. R. Green, J. Exp. Med., 1995, 182, 1545-1556.

7 R. F. A. Zwaal and A. J. Schroit, Blood, 1997, 89, 1121-1132.

8 F. -X. Contreras, L. Sánchez-Magraner, A. Alonso and F. M. Goñi, FEBS Lett., 2010, 584, 1779-1786.

9 M. Mourdjeva, D. Kyurkchiev, A. Mandinova, I. Altankova, I. Kehayov and S. Kyurkchiev, Apoptosis, 2005, 10, $209-217$.

10 V. A. Fadok, D. R. Voelker, P. A. Campbell, J. J. Cohen, D. L. Bratton and P. M. Henso, J. Immunol., 1992, 148, 2207-2216.

11 E. M. Bevers and P. L. Williamson, Physiol. Rev. 2016, 96, 605-645.

12 A. A. Neves, K. M. Brindle, Biochim. Biophys. Acta-Rev. Cancer, 2006, 1766, 242-261.

13 Y. Wu, D. Xing, S. Luo, Y. Tang and Q. Chen, Cancer Lett., 2006, 235, 239-247.

14 L. E. Edgington, A. B. Berger, G. Blum, V. E. Albrow, M. G. Paulick, N. Lineberry and M. Bogyo, Nat. Med. $2009,15,967-973$.

15 H. Shi, R. T. K. Kwok, J. Liu, B. Xing, B. Z. Tang and B. Liu, J. Am. Chem. Soc., 2012, 134, 17972-17981.

16 P. R. Walker, J. Leblanc, B. Smith, S. Pandey and M. Sikorska, Methods, 1999, 17, 329-338.

17 C. Ferlini and G. Scambia, Nat. Protoc., 2007, 2, 3111-3114.

18 D. -F. Suen, K. L. Norris and R. J. Youle, Genes Dev., 2008, 22, 1577-1590.

19 V. V. Shynkar, A. S. Klymchenko, C. Kunzelmann, G. Duportail, C. D. Muller, A. P. Demch enko, J.-M. Freyssinet and Y. Mély, J. Am. Chem. Soc., 2007, 129, 2187-2193.

20 Z. Darwich, A. S. Klymchenko, O. A. Kucherak, L. Richert and Y. Mély, Biochim. Biophys. Acta, Biomembr., 2012, 1818, $3048-3054$.

21 V. Gerke, S. E. Moss, Physiol. Rev., 2002, 82, 331-371.

22 A. P. Demchenko, Cytotechnology, 2013, 65, 157-172.

23 M. A. Lizarbe, J. I. Barrasa, N. Olmo, F. Gavilanes and J. Turnay, Int. J. Mol. Sci., 2013, 14, 2652-2683.

24 J. Dachary-Prigent, J. -M. Pasquet, J. -M. Freyssinet and A. T. Nurden, Biochem., 1995, 34, 11625-11634.

25 F. A. Kuypers, R. A. Lewis, M. Hua, M. A. Schott, D. Discher, J. D. Ernst and B. H. Lubin, Blood, 1996, 87, 1179-1187.

26 D. R. Rice, K. J. Clear and B. D. Smith, Chem. Commun., 2016, 52, 8787-8801.

27 B. A. Smith, W. J. Akers, W. M. Leevy, A. J. Lampkins, S. Xiao, W. Wolter, M. A. Suckow, S. Achilefu and B. D. Smith, J. Am. Chem. Soc., 2010, 132, 67-69.

28 D. R. Rice, H. Gan and B. D. Smith, Photochem. Photobiol. Sci., 2015, 14, 1271-1281.

29 K. J. Clear, K. M. Harmatys, D. R. Rice, W. R. Wolter, M. A. Suckow, Y. Wang, M. Rusckowski and B. D. Smith, Bioconjugate Chem., 2016, 27, 363-375.

30 Q. Hu, M. Gao, G. Feng, X. Chen and B. Liu, ACS Appl. Mater. Interfaces, 2015, 7, 4875-4882.

31 T. S. Jarvis, F. M. Roland, K. M. Dubiak, P. W. Huber and B. D. Smith, J. Mater. Chem. B, 2018, 6, 4963-4971.

32 V. E. Zwicker, B. L. Oliveira, J. H. Yeo, S. T. Fraser, G. J. L. Bernardes, E. J. New and K. A. Jolliffe, Angew. Chem. Int. Ed., In Press, DOI: 10.1002/anie.201812489.

33 A. S. Klymchenko, Acc. Chem. Res., 2017, 50, 366-375.

34 M. K. Kuimova, Phys. Chem. Chem. Phys., 2012, 14, 12671-12686.

35 M. A. Haidekker and E. A. Theodorakis, Org. Biomol. Chem., 2007, 5, 1669-1678.

36 M. K. Kuimova, G. Yahioglu, J. A. Levitt and K. Suhling, J. Am. Chem. Soc., 2008, 130, 6672-6673.

37 A. Vyšniauskas, I. López-Duarte, N. Duchemin, T. T. Vu, Y. Wu, E. M. Budynina, Y. A. Volkova, E. Peña Cabrera, D. E. RamírezOrnelas, M. K. Kuimova, Phys. Chem. Chem. Phys. 2017, 19, 25252-25259.

38 J. A. Levitt, M. K. Kuimova, G. Yahioglu, P. -H. Chung, K. Suhling and D. Phillips, J. Phys. Chem. C, 2009, 113, $11634-11642$.

39 I. Lopez-Duarte, T. T. Vu, M. A. Izquierdo, J. A. Bull and M. K. Kuimova, Chem. Commun., 2014, 50, 5282-5284.

40 P. S. Sherin, I. Lopez-Duarte, M. R. Dent, M. Kubankova, A. Vysniauskas, J. A. Bull, E. S. Reshetnikova, A. S. Klymchenko, Y. P. Tsentalovich and M. K. Kuimova, Chem. Sci., 2017, 8, 3523-3528.

41 M. Kubankova, I. Lopez-Duarte, J. A. Bull, D. M. Vadukul, L. C. Serpell, M. S. Victor, E. Stride and M. K. Kuimova, Biomaterials, 2017, 139, 195-201.

42 W. L. Goh, M. Y. Lee, T. X. Lim, J. S. Chua, S. Brenner, F. J. Ghadessy and Y. N. Teo, Sci. Rep., 2018, 8, 12946-12958.

43 I. A. Karpenko, Y. Niko, V. P. Yakubovskyi, A. O. Gerasov, D. Bonnet, Y. P. Kovtun and A. S. Klymchenko, J. Mater. Chem. C, 2016, 4, 3002-3009.

44 I. A. Karpenko, R. Kreder, C. Valencia, P. Villa, C. Mendre, B. Mouillac, Y. Mély, M. Hibert, D. Bonnet and A. S. Klymchenko, ChemBioChem, 2014, 15, 359-363.

45 D. Zamora-Olivares, T. S. Kaoud, K. N. Dalby and E. V. Anslyn, J. Am. Chem. Soc., 2013, 135, 14814-14820.

46 A. C. Benniston and G. Copley, Phys. Chem. Chem. Phys., 2009, 11, 4124-4131.

47 T. Suhina, S. Amirjalayer, S. Woutersen, D. Bonn, A. M. Brouwer, Phys. Chem. Chem. Phys. 2017, 19, 19998-20007.

48 T. FÖrster and G. Hoffmann, Z. Phys. Chem., 1971, 75, 63-76.

49 C. A. Belmokhtar, J. Hillion and E. Segal-Bendirdjian, Oncogene, 2001, 20, 3354-3362.

50 I. Vermes, C. Haanen, H. Steffens-Nakken, C. Reutelingsperger, J. Immunol. Methods, 1995, 184, 39-51. 